\title{
Environmental Trace-Element Analysis Using a Benchtop Total Reflection X-Ray Fluorescence Spectrometer
}

\author{
Hagen StOSNACH \\ Röntec AG, Schwarzschildstrasse 12, D-12489 Berlin, Germany
}

\begin{abstract}
Total reflection X-ray fluorescence (TXRF) analysis is an established technique for trace-element analysis in various types of samples. Though expensive large-scale systems restricted the applications in the past, in this study the capability of a benchtop system for trace elemental analysis is reported. The suitability of this system for the mobile on-site analysis of heavy metal contaminated soils and sediments is reported as well as the possibilities and restrictions of TXRF for additional applications, including trace-element analysis of water, glass and biological samples.
\end{abstract}

(Received March 30, 2005; Accepted May 6, 2005)

\section{Introduction}

Total reflection X-ray fluorescence (TXRF) analysis is a versatile tool for trace-element analysis applicable to various sample types, especially liquids and powdered or micro samples. To perform analysis under total-reflection conditions, the samples must be provided as a thin film. For liquid samples, this is done by preparing 5 to $30 \mu \mathrm{l}$ of the sample onto a reflective sample carrier (in most cases, made of quartz- or acrylic glass); the volatile portions are removed by applying heat or vacuum. Powdered samples are prepared in a similar way as suspensions, or directly onto the sample carrier. A direct preparation can be applied to micro amounts of samples, too. Samples prepared by this way, can be analyzed qualitatively without further treatment.

The preparation of samples as a thin layer precludes matrix effects, like absorption or secondary excitation. Thus quantification in TXRF analysis can be done by an internal standard. The internal standard must be added to the sample before quantitative analysis. The requirements on the internal standard are that it is not present in the sample itself, and that the standard concentration is in the same range as the elements in the sample. For totally unknown samples, these parameters can be determined by means of qualitative analysis.

Trace-element analysis by means of TXRF is widely reported for wafer surface analysis, ${ }^{1}$ organic and inorganic chemistry, ${ }^{2}$ environmental and aerosol analysis ${ }^{3,4}$ as well as numerous additional applications. ${ }^{5,6}$ The benefits of this analytical technique are non-destructive operation, the requirement for extremely minute sample amounts and simplicity of analysis, including sample preparation and quantification.

Most of the published TXRF analyses were performed, using large-scaled instruments with high-power X-ray tubes, demanding water-cooling systems and liquid-nitrogen cooled detectors. The spectrometer used for the present study was a benchtop system with an air-cooled low-power X-ray tube and a Peltier cooled silicon drift detector (SDD).

Just recently, the instrument sensitivity was shown to be similar to large-scale laboratory systems. ${ }^{7}$ The capability of this instrument for trace-element analysis in different sample types, including soils, sediments, water, glass and biological samples, has been tested successfully.

\section{Instrumentation}

For all investigations, a benchtop TXRF spectrometer (PicoTAX, Roentec Berlin, Germany) was used. A summary of the technical specifications of the PicoTAX spectrometer can be found in Table 1.

\section{On-Site Analysis of Contaminated Soil- and Sediment Samples}

The suitability of the PicoTAX spectrometer for the mobile analysis of heavy metals in soil- and sediment samples was tested during the Superfund Innovative Technology Evaluation Program (SITE) organized by the United States Environmental Protection Agency (US EPA), conducted by the supervising company TetraTech Inc. During this study, different portable $\mathrm{XRF}$ systems were tested under realistic conditions for the onsite, respectively, near-site analysis of heavy metal contaminated areas. The complete analytical equipment was set up in a cottage equipped with a normal power connection. The

Table 1 Technical specifications of the TXRF spectrometer PicoTAX

\begin{tabular}{ll}
\hline X-Ray tube & $50 \mathrm{kV}, 1 \mathrm{~mA}$, Mo target \\
Element range & Al to Y, Pd to U \\
Optics & Multilayer Ni/C, 17.5 keV, 80\% reflectivity \\
Detector & Drift chamber, $10 \mathrm{~mm}^{2},<160 \mathrm{eV}$ resolution \\
Carrier & Quartz or other materials, $30 \mathrm{~mm}$ diameter \\
Sample station & Type 1: single disc changer \\
& $\begin{array}{l}\text { Type 2: sample station with cassette for 25 } \\
\text { discs }\end{array}$ \\
Control & PC, data transfer via serial interface \\
Size, weight & $600 \times 300 \times 450 \mathrm{~mm}, 37 \mathrm{~kg}$ \\
Power consumption & $150 \mathrm{~W}$ \\
\hline
\end{tabular}


Table 2 Measurement results for the fresh water reference sample "NIST 1640" (all values in $\mu \mathrm{g} / \mathrm{L}$ )

\begin{tabular}{|c|c|c|c|c|c|c|c|c|c|c|c|c|c|c|c|}
\hline Element & $\mathrm{Be}$ & B & $\mathrm{Na}$ & $\mathrm{Mg}$ & $\mathrm{Al}$ & $\mathrm{P}$ & $S$ & $\mathrm{Cl}$ & K & $\mathrm{Ca}$ & V & $\mathrm{Cr}$ & $\mathrm{Mn}$ & $\mathrm{Fe}$ & $\mathrm{Co}$ \\
\hline Certified & $\begin{array}{c}34.9 \\
( \pm 0.41)\end{array}$ & $\begin{array}{c}301 \\
( \pm 6.1)\end{array}$ & $\begin{array}{l}29350 \\
( \pm 310)\end{array}$ & $\begin{array}{l}5819 \\
( \pm 56)\end{array}$ & $\begin{array}{c}52 \\
( \pm 1.5)\end{array}$ & $\begin{array}{l}\text { No } \\
\text { data }\end{array}$ & $\begin{array}{l}\text { No } \\
\text { data }\end{array}$ & $\begin{array}{l}\text { No } \\
\text { data }\end{array}$ & $\begin{array}{c}994 \\
( \pm 27)\end{array}$ & $\begin{array}{l}7045 \\
( \pm 89)\end{array}$ & $\begin{array}{c}13.0 \\
( \pm 0.4)\end{array}$ & $\begin{array}{c}38.6 \\
( \pm 1.6)\end{array}$ & $\begin{array}{c}122 \\
( \pm 1.1)\end{array}$ & $\begin{array}{c}34.3 \\
( \pm 1.6)\end{array}$ & $\begin{array}{c}20.3 \\
( \pm 0.3)\end{array}$ \\
\hline PicoTAX & $\begin{array}{l}\text { Not } \\
\text { det. }\end{array}$ & $\begin{array}{l}\text { Not } \\
\text { det. }\end{array}$ & $<$ LLD & 5227 & $<$ LLD & 63 & 2546 & 104 & 1017 & 8136 & 13.4 & 33.2 & 112.4 & 43.3 & 19.3 \\
\hline LLD & & & & 874 & & & & & 6.89 & 4.90 & 2.0 & 1.7 & 1.3 & 0.8 & 0.9 \\
\hline Element & $\mathrm{Ni}$ & $\mathrm{Cu}$ & $\mathrm{Zn}$ & As & $\mathrm{Se}$ & $\mathrm{Br}$ & $\mathrm{Rb}$ & $\mathrm{Sr}$ & Mo & $\mathrm{Ag}$ & $\mathrm{Cd}$ & $\mathrm{Sb}$ & $\mathrm{Ba}$ & $\mathrm{Pb}$ & \\
\hline Certified & $\begin{array}{c}27.4 \\
( \pm 0.8)\end{array}$ & $\begin{array}{c}85.2 \\
( \pm 1.2)\end{array}$ & $\begin{array}{c}53.2 \\
( \pm 1.1)\end{array}$ & $\begin{array}{c}26.7 \\
( \pm 0.4)\end{array}$ & $\begin{array}{c}22.0 \\
( \pm 0.5)\end{array}$ & $\begin{array}{l}\text { No } \\
\text { data }\end{array}$ & $\begin{array}{c}2.0 \\
( \pm 0.02)\end{array}$ & $\begin{array}{c}124 \\
( \pm 0.7)\end{array}$ & $\begin{array}{c}46.8 \\
( \pm 0.3)\end{array}$ & $\begin{array}{c}7.62 \\
( \pm 0.2)\end{array}$ & $\begin{array}{c}22.8 \\
( \pm 1.0)\end{array}$ & $\begin{array}{c}13.8 \\
( \pm 0.4)\end{array}$ & $\begin{array}{c}148 \\
( \pm 2.2)\end{array}$ & $\begin{array}{c}27.9 \\
( \pm 0.1)\end{array}$ & \\
\hline PicoTAX & 26.9 & 89.09 & 65.9 & 27.0 & 22.2 & 1.2 & 1.8 & 128.0 & $\begin{array}{l}\text { Not } \\
\text { det. }\end{array}$ & $\begin{array}{l}\text { Not } \\
\text { det. }\end{array}$ & $\begin{array}{l}\text { Not } \\
\text { det. }\end{array}$ & $\begin{array}{l}\text { Not } \\
\text { det. }\end{array}$ & 155 & 27.9 & \\
\hline LLD & 0.7 & 0.6 & 0.4 & 0.4 & 0.3 & 0.4 & 0.4 & 4.1 & & & & & 4.1 & 0.4 & \\
\hline
\end{tabular}

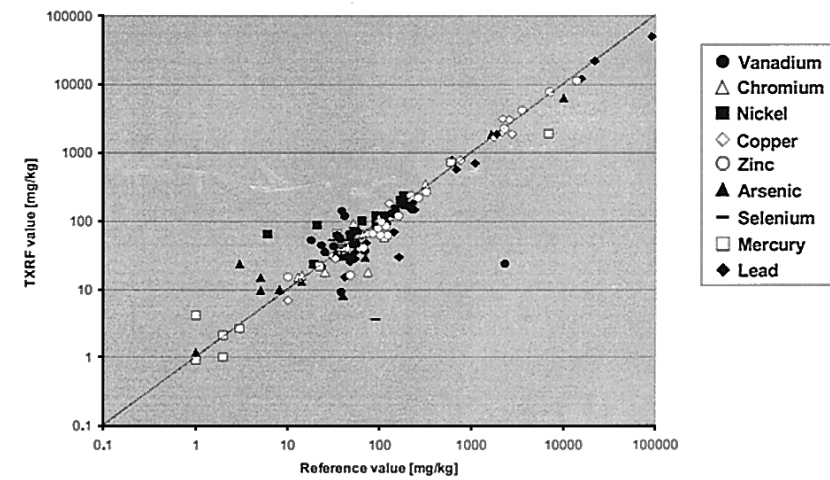

Fig. 1 Comparison of reference values (derived by atomic spectroscopy) and on-site TXRF results for soil- and sediment samples.

samples were provided as dried and grinded powders.

For evaluation purposes, all samples were analyzed by independent external laboratories, in charge of the EPA, using standardized atomic spectroscopic methods.

Sample preparation was done by weighing an amount of approximately $25 \mathrm{mg}$ of sample powder after manual grinding in an agate mortar. This sample material was then suspended in $2.5 \mathrm{~mL}$ of a $10 \%$ aqueous solution of Triton X-100. Triton X100 is an organic compound, often used for the viscosity adjustment of solutions, e.g. for gas chromatography. Applied for TXRF sample preparation, it enhances the homogeneity of samples.

For quantification purposes, $40 \mu \mathrm{L}$ of a Ga solution (Merck, 1 $\mathrm{g} / \mathrm{L})$ was added to all samples as an internal standard. After thorough homogenization, $10 \mu \mathrm{L}$ of the resulting suspension was transferred onto a quartz glass disc and dried on a heating plate. The typical measurement time was $600 \mathrm{~s}$ per sample.

A comparison of the TXRF results to the reference values is presented in Fig. 1.

A detailed evaluation of the measurement for the 13 most interesting elements of this study shows the possibilities and limitations of the present application. Three elements, antimony, cadmium and silver could not be detected in the given concentration ranges. Since the PicoTAX TXRF spectrometer uses a molybdenum tube for excitation, these elements can be detected by means of their low-intensity L-lines only. In soil and sediment samples, these lines are in most cases partially or completely overlapped by the strong K-lines of the matrix elements, calcium and potassium, which prevents a quantitative determination. Sporadic incorrect results for chromium, nickel and arsenic were observed, when ratios between overlapping elements, like lead and arsenic were in the range of 1:100 or higher. Reproducible results were achieved for vanadium, cobalt, zinc, selenium, mercury and lead.

In summary, it can be stated, that TXRF spectroscopy can be a versatile tool at least for a fast and simple screening of heavy metals in soil and sediment samples. Using the described benchtop spectrometer, these measurements can even be performed on-site or near-site, respectively.

\section{Water Analysis}

One of the most common applications for TXRF is trace element analysis in liquid samples, like natural water. To evaluate the performance of the PicoTAX spectrometer for this type of application, a certified reference fresh-water sample (NIST 1640) was analyzed.

Sample preparation was done by adding $10 \mu \mathrm{L}$ of a Gasolution (Merck, $1 \mathrm{~g} / \mathrm{L}$ ) to a $1 \mathrm{~mL}$ portion of the sample. After thorough homogenization, $10 \mu \mathrm{L}$ was prepared onto a quartz glass disc and subsequently dried in a desiccator. For controlling the reproducibility, 10 samples of the reference standard were prepared. The measurement time was set to 1000 s.

The results of the water analyses are summarized in Table 2 . The listed detection limits were calculated using the following formula according to Klockenkämper: ${ }^{6}$

$$
\mathrm{LLD}=3 \times \frac{c}{N_{\text {net }}} \times \sqrt{\left(2 N_{\text {back }}\right)},
$$

where $c$, concentration of element; $N_{\text {net }}$, net countrate; $N_{\text {back }}$, background countrate.

Good correlations between the certified and measured values could be achieved for the elements magnesium, potassium, calcium, vanadium, chromium, manganese, cobalt, nickel, copper, arsenic, selenium, bromine, rubidium, strontium, barium and lead. The overestimations for iron and zinc were most probably caused by contamination during the sample preparation. Beryllium, boron and sodium as light elements could not be analyzed in the given concentrations due to the absorption of their X-ray fluorescence signals in the air atmosphere of the instrument. The elements silver, cadmium and antimony could be detected using a molybdenum-tube just 
Table 3 Results for stability and reproducibility measurements of the reference standard NIST 1640

\begin{tabular}{lcccccccccccccccccccccccc}
\hline \multicolumn{1}{c}{ Element } & $\mathrm{Mg}$ & $\mathrm{S}$ & $\mathrm{Cl}$ & $\mathrm{K}$ & $\mathrm{Ca}$ & $\mathrm{V}$ & $\mathrm{Cr}$ & $\mathrm{Mn}$ & $\mathrm{Fe}$ & $\mathrm{Co}$ & $\mathrm{Ni}$ & $\mathrm{Cu}$ & $\mathrm{Zn}$ & $\mathrm{As}$ & $\mathrm{Se}$ & $\mathrm{Br}$ & $\mathrm{Rb}$ & $\mathrm{Sr}$ & $\mathrm{Ba}$ & $\mathrm{Pb}$ \\
\hline Concentration $(\mu \mathrm{g} / \mathrm{L})$ & 5819 & 2546 & 104 & 994 & 7045 & 13.0 & 38.6 & 122 & 34.3 & 20.3 & 27.4 & 85.2 & 53.2 & 26.7 & 22.0 & 1.2 & 1.8 & 124 & 148 & 27.9 \\
Stability, \% & 55.1 & 1.9 & 9.4 & 1.1 & 0.6 & 8.5 & 4.6 & 1.5 & 4.7 & 3.4 & 3.3 & 1.5 & 1.0 & 2.8 & 2.8 & 17.5 & 13.8 & 0.8 & 8.1 & 3.6 \\
Reproducibility, \% & 26.0 & 4.3 & 5.3 & 3.2 & 1.8 & 11.7 & 5.7 & 1.8 & 6.2 & 4.0 & 2.6 & 1.5 & 2.7 & 3.5 & 1.5 & 23.9 & 18.3 & 2.5 & 3.4 & 4.0 \\
\hline
\end{tabular}

Table 4 Comparison of TXRF and CV-AAS values for the mercury content

\begin{tabular}{cccc}
\hline Method & Analysis & $\begin{array}{c}\mathrm{Hg} / \\
\mathrm{mg} \mathrm{kg}^{-1}\end{array}$ & $\begin{array}{c}\text { Standard deviation/ } \\
\mathrm{mg} \mathrm{kg}^{-1}\end{array}$ \\
\hline CV-AAS & 1 & 2.8 & $0.3(n=10)$ \\
& 2 & 2.9 & $0.3(n=7)$ \\
& 3 & 2.13 & \\
& 5 & 2.19 & 0.12 \\
TXRF & 6 & 2.42 & $0.07(n=6)$ \\
& PicoTAX & 2.5 & $0.3(n=6)$ \\
\hline
\end{tabular}

by means of their low intensity L-lines only. In addition to the absorption of these lines, they were strongly overlapped by the K-lines of the matrix elements potassium and calcium. Molybdenum could not be analyzed because of the presence in the tube spectra. For the analyzed elements phosphorus, sulfur, chlorine and bromine, no reference values were available.

Two additional important values for evaluating analytical results are the instrument stability and the reproducibility of the measurement results. To check for the instrument stability, one NIST 1640 sample was analyzed 10 times using a measurement time of $1000 \mathrm{~s}$, including removal and loading of the sample for each measurement. The reproducibility was mainly influenced by the sample preparation. Because of this, ten NIST 1640 samples were prepared and subsequently analyzed with a measurement time of $1000 \mathrm{~s}$.

The results of these measurements are summarized in Table 3. For all elements, with the exception of magnesium, vanadium, bromine and rubidium, very low stability and reproducibility values could be achieved. The high values for these four elements are connected to the low counting statistics caused by the low sensitivity of the instrument for light elements (magnesium), disturbances by line overlaps between elements with high (barium) and comparably low (vanadium) concentrations or elements present in concentrations close to their detection limit (bromine and rubidium).

\section{Further Applications}

Recently, two additional applications that demonstrated the capability of the TXRF method have been tested.

The analysis of mercury traces in glass samples is complicated due to the chemical and physical properties of this element. Typically, mercury is analyzed by means of cold vapor atomic adsorption spectroscopy ${ }^{8}$ which requires an expensive samplepreparation process.

For quantitative analysis by TXRF, the sample material was prepared as a suspension, similar to soil and sediment samples, described above, and measured in triplicate for $1000 \mathrm{~s}$.

In Table 4 the TXRF values are compared to those of external laboratories based on the ICG/TC2 method (data to be

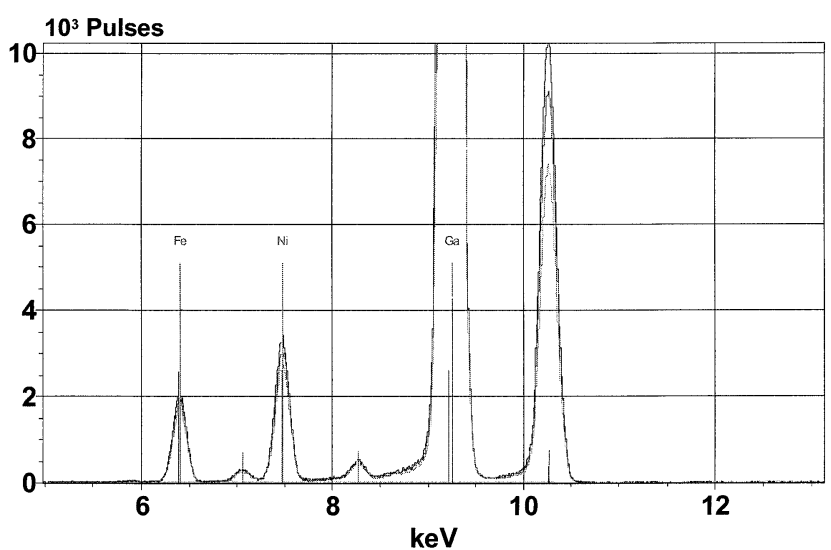

Fig. 2 TXRF spectra of three different peptide samples.

published) originating from a round robin, performed by the Germany Society of Glass Technology. The target of this round robin was to apply additional methods to this type of analysis. No additional TXRF or common XRF spectrometers were available for these measurements. A very good concordance of the TXRF- and the CV-AAS values was observed. Thus, it can be concluded that TXRF is a suitable technique for the analysis of mercury in recycling glass with the major benefit of an easy and fast sample preparation. Furthermore, TXRF avoids digestion of the sample material and any external calibration. In addition, the risk of falsified results caused by memory effects, as described by the ICG/TC $2,{ }^{8}$ can be completely avoided.

A disadvantage of the TXRF technique is the comparably long measurement time. This factor is almost negligible if a complete analysis, including sample preparation and pretreatment, is taken into account.

Analyzing trace elements in biological samples frequently bears the problem of minute sample amounts. During measurements for a project in cooperation with the Department of Physics of the Freie Universität Berlin, several peptide concentrate samples were analyzed by means of TXRF for their iron and nickel concentrations. During the extraction process, just an amount of 3 to $5 \mu \mathrm{l}$ of each sample could be gained.

Dilution of the sample material, which is necessary for other analytical methods, like Atomic Adsorption Spectroscopy (AAS), had to be avoided. Thus, sample preparation was done by transferring $2 \mu \mathrm{l}$ of the sample material onto a quartz glass disc, and subsequently adding $2 \mu \mathrm{l}$ of a Ga solution for internal standardization. After drying in a desiccator the samples were analyzed for $1000 \mathrm{~s}$.

Figure 2 indicates that even using an extremely small sample amount, a very good counting statistic could be achieved. The ratio values were determined with values of 0.83 to 0.88 . Good correlations between TXRF and AAS values could be observed for all analyzed samples. ${ }^{9}$ 


\section{Summary}

The data presented in this paper indicate the versatility of TXRF analysis for trace-element analysis in various sample types. The sample preparation for TXRF is comparably easy and quantification does not require external calibrations and correction for matrix effects. All detectable elements are analyzed simultaneously, and even extremely small sample amounts can be analyzed accurately. When applying a benchtop system, analyzes can even be performed on-site or near-site, respectively.

The disadvantages are comparably long measurement times and restrictions with regard to some elements (light and L-line elements like cadmium, silver and antimony).

\section{Acknowledgements}

The author would like to thank United States Environmental Protection Agency (Washington, D.C.), Tetra Tech Inc. (Pasadena, CA), Germany Society of Glass Technology (Offenbach, Germany), and Department of Physics, Freie Universität Berlin, for their support.

\section{References}

1. L. Fabry, S. Pahlke, L. Kotz, P. Wobrauschek, and C. Streli, Fresenius' J. Anal. Chem., 1999, 363, 98.

2. A. Exner, M. Theisen, U. Panne, and R. Niessner, Fresenius' J. Anal. Chem., 2000, 366, 254.

3. M. Mages, S. Woelfl, and W. Von Tümpling, Spectrochim. Acta, Part B, 2001, 56, 2209.

4. M. Schmeling, Adv. X-ray Anal., 2002, 45, 544.

5. J. P. Potts, A. T. Ellis, P. Kregsamer, J. Marshall, C. Streli, M. West, and P. Wobrauschek, J. Anal. At. Spectrom., 2001, 16, 1217.

6. R. Klockenkämper, "Total Reflection X-Ray Analysis", 1997, Wiley, New York.

7. M. Mages, S. Woelfl, M. Óvári, and W. Tümpling, Spectrochim. Acta, Part B, 2003, 58, 2129.

8. International Commission on Glass, CV-AAS, Norm 2/99. 1194-ICG/TC2, 1999.

9. T. Buhrke, S. Löscher, O. Lenz, E. Schlodder, I. Zebger, L. K. Andersen, P. Hildebrandt, W. Meyer-Klaucke, H. Dau, B. Friedrich, and M. Haumann, J. Biol. Chem., 2005, in press. 